REGARDS

SUR L'ECONOMIE ALLEMANDE

BULLETIN ECONOMIQUE DU CRAC

\section{Regards sur l'économie allemande}

Bulletin économique du CIRAC

107 | 2012

Varia

\title{
Europe : la guerre d'usure franco-allemande continue
}

René Lasserre

\section{(2) OpenEdition}

1 Journals

Édition électronique

URL : http://journals.openedition.org/rea/4487

DOI : $10.4000 /$ rea.4487

ISBN : 978-2-8218-1424-0

ISSN : 1965-0787

Éditeur

CIRAC

Édition imprimée

Date de publication : 20 décembre 2012

Pagination : 1-2

ISSN : 1156-8992

Référence électronique

René Lasserre, «Europe : la guerre d'usure franco-allemande continue », Regards sur l'économie allemande [En ligne], 107 | décembre 2012, mis en ligne le 14 janvier 2013, consulté le 22 septembre 2020. URL : http://journals.openedition.org/rea/4487 ; DOI : https://doi.org/10.4000/rea.4487 


\section{Europe : la guerre d'usure franco-allemande continue}

Outre la confirmation attendue du soutien à la Grèce, le Sommet européen des 14 et 15 décembre 2012 a permis de franchir une nouvelle étape sur la voie du sauvetage de l'Euro en jetant les bases d'un cadre unifié de supervision des 200 principales banques européennes. Préfigurant une future Union bancaire, qui entrera en vigueur à compter de 2014, ce système de contrôle intégré, placé sous l'autorité de la BCE, devra garantir la solvabilité et, au besoin, assurer la recapitalisation des banques pour leur permettre de faire face aux risques inhérents au rachat de la dette souveraine des Etats.

Ce résultat n'était pas gagné d'avance, vu la complexité du dispositif et les oppositions qu'avaient suscitées sa conception et son architecture entre Berlin et Paris au moment du lancement de cette initiative lors du sommet d'octobre dernier. Ce n'est, une fois de plus, qu'au prix d'un bas de fer très serré et de concessions mutuelles entre les deux gouvernements, portant à la fois sur la délimitation du périmètre souhaitable des établissements et la séparation stricte à observer entre supervision bancaire et politique monétaire, qu'un cadre commun de règles et de principes a pu être défini et adopté entre les membres de la zone Euro. Ainsi pourra être édifié le dernier rempart qui permettra de mettre durablement l'Euro à l'abri de la pression spéculative des marchés.

Mais autant la supervision bancaire marque une avancée décisive dans la consolidation de l'Union monétaire, autant le sommet qui vient de s'achever se révèle décevant au regard de l'approfondissement annoncé et tant attendu de l'Union économique. Du projet ambitieux présenté le 28 novembre par le Président de la Commission, il ne reste plus grand' chose. Celui-ci prévoyait sur le moyen terme un processus de décision et de surveillance économique impliquant des réformes structurelles contraignantes entre les Etats et la mise en place d'un budget spécifique pour la zone Euro. Le pan Barroso a été purement et simplement taillé en pièces et relégué à plus tard. La feuille de route confiée au Président du Conseil Européen se limite désormais à proposer, à l'horizon de juin 2013, et dans le cadre institutionnel existant, un programme d'actions relatives à la coordination des réformes économiques et à la promotion de la dimension sociale de la zone Euro, à la définition de contrats de compétitivité et de croissance entre les autorités européennes et les Etats, assortis au besoin de mécanismes modestes de solidarité financière. Un catalogue composite a minima qui réduit la capacité budgétaire de la zone Euro à un fonds de solidarité d'ampleur limitée et laisse pour l'instant dans le flou la portée des engagements souscrits.

Une fois de plus, la France et l'Allemagne, à défaut d'accord sur l'essentiel - c'est-à-dire sur l'équilibre à définir entre d'un côté les disciplines économiques et les responsabilités politiques communes à assumer et, de l'autre, les efforts de solidarité à consentir -, se réfugient dans un attentisme de connivence qui ne fait que prolonger la guerre d'usure engagée depuis juin 2012. A quelques mois des élections fédérales de l'automne 2013, Angela Merkel n'a aucun intérêt à souscrire devant son

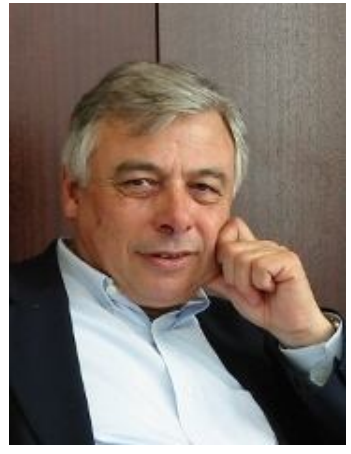

Prof. René Lasserre, Directeur du CIRAC 
opinion à de nouveaux engagements budgétaires européens sous la pression d'un partenaire français qui demeure à ce point réticent à remettre son économie en ordre de marche. A l'inverse, François Hollande peut se prévaloir du marasme persistant que la stratégie allemande de consolidation financière impose à la zone Euro pour cultiver sa différence. En continuant de se faire l'avocat tribunicien de la croissance et de la solidarité au bénéfice des pays les plus sévèrement touchés par la crise, le Président français croit pouvoir se ménager un espace politique en Europe, tout en gagnant du temps vis-à-vis de son électorat pour étaler et minimiser l'ampleur des ajustements qu'il doit opérer au plan domestique.

Il n'est pas sûr qu'à ce jeu l'équation française ait quelque chance d'être gagnante. Tout d'abord parce que, quel que soit leur résultat, les élections fédérales de l'automne 2013 n'infléchiront pas foncièrement la donne politique allemande ni les invariants de la politique européenne de notre partenaire. Ensuite, parce que la réforme du modèle économique et social français constitue à la fois un défi politique intérieur incontournable et un impératif indissociable du choix européen de la France. Chercher à s'en affranchir par des demi-mesures ou en empruntant des chemins de traverse, et ce alors même que l'avenir du projet européen est en jeu, ne constitue pas un objectif raisonnable.

René Lasserre, le 18 décembre 2012 